\title{
INOVAÇÕES TECNOLÓGICAS NA BIOMINERAÇÃO DE MINÉRIOS LATERÍTICOS DE NÍQUEL E COBALTO
}

Ellen Cristine Giese

\section{Resumo}

Abusca por melhoria da eficiência energética no setor automotivo representa um desafio para o desenvolvimento de baterias automotivas que afeta o setor minerometalúrgico. Muitas destas baterias são baseadas no uso do cobalto, um mineral estratégico considerado subproduto da mineração do níquel. Com o esgotamento contínuo de minérios de sulfeto de níquel de alto teor, faz-se necessário o desenvolvimento de novas tecnologias para a recuperação destes metais a partir das lateritas. $\mathrm{O}$ uso de micro-organismos capazes de solubilizar metais a partir de minérios de baixo teor através da geração biológica de ácidos "in situ" é uma alternativa interessante e que já vem sendo empregada. Assim, oobjetivo deste trabalho foi avaliar o perfil das competências tecnológicas relacionadas aos processos de biolixiviação de níquel e cobalto através do estudo das patentes depositadas nas bases de dados Patent Scope e Google Patents. Observou-se que, entre os anos de 1995 e 2017, cerca de 42 patentes foram depositadas.A partir dos resultados obtidos nesta pesquisa, foi traçado um paralelo entre os depósitos de patentes e os dados econômicos do mercado. A análise dos dados obtidos permitiu descrever as tecnologias preferencialmente protegidas dos processos de bioextração de níquel e cobalto.

Palavras-chave: Biolixiviação; Minérios lateríticos; Níquel; Cobalto.

\section{TECHNOLOGICAL INNOVATIONS IN THE BIOMINERATION OF NICKEL AND COBALT FROM LATERITES}

\begin{abstract}
The search for better energy efficiency in the automotive sector represents a challenge for the development of automotive batteries that affect the mining and metallurgical sector. Many of these batteries are based on the use of cobalt, a strategic mineral considered as a by-product of nickel mining. With the continuous depletion of high-grade nickel sulfide ores, it is necessary to develop new technologies for the recovery of these metals from the laterites. The use of microorganisms capable of solubilizing metals from low-grade ores by the biological generation of acids in situ is an interesting alternative and has already been used. Thus, the objective of this work was to evaluate the profile of technological competencies related to nickel and cobalt bioleaching processes through the study of patents deposited in the Patent Scope and Google Patents databases. It was observed that, between 1995 and 2017, about 42 patentswere deposited. From the results obtained in this research, a parallel was drawn between the patent deposits and the economic data of the market. The analysis of the obtained data allowed to describe the technologies preferentially protected of the processes of bioextraction of nickel and cobalt.
\end{abstract}

Keywords: Bioleaching; Lateritic ores; Nickel; Cobalt.

\section{INTRODUÇÃO}

Com a elevada demanda por metais valiosos e minerais estratégicos, impulsionada pelo crescimento econômico mundial e pelo desenvolvimento de novas tecnologias dos últimos anos, as mineradoras tem se empenhado na busca constante por melhor aproveitamento de suas reservas minerais. Por consequência, a exploração de reservas de minérios cada vez mais pobres, denominados também como minérios de baixo teor, antes tidos como não econômicos, tem sido justificada.

Os depósitos de baixo teorrepresentam até três quartos das reservas mundiais para determinados metais, entre eles o níquel e o cobalto [I]. Cerca de $60 \%$ das reservas disponíveisdestes metais correspondem a minérios lateríticos, e os $40 \%$ restantes correspondem aos minérios

'Centro de Tecnologia Mineral - CETEM, Ministério da Ciência, Tecnologia, Inovações e Comunicações - MCTIC, Rio de Janeiro, RJ, Brasil.

E-mail: egiese@cetem.gov.br

2176-1523 @ 2019 Associação Brasileira de Metalurgia, Materiais e Mineração. Published by ABM. This is an open access paper, published under the Creative Commons CC BY-NC-ND license (Attribution-NonCommercial-NoDerivs) - https://creativecommons.org/licenses/ by-nc-nd/4.0/. 
sulfetados. Dentre os minérios lateríticos, predominam os limoníticos (60\%-70\%) sobre os saprolíticos (30\%-40\%). De acordo com levantamento realizado por Rodrigues [2], em 208 Mt de minério laterítico, há cerca de I, I7\% de níquel ( $1955 \mathrm{MtNi}$ ) e somente $0,082 \%$ de cobalto $(0,147 \mathrm{MtCo})$. A maior jazida de níquel sulfetado do Brasil, localizada em Americano do Brasil, contém aproximadamente $0,62 \%$ de níquel, $0,65 \%$ de cobre e $0,04 \%$ de cobalto.

Em 2017, os preços do níquel aumentaram 27,51\% devido à demanda sólida de aço inoxidável da China. Com a demanda crescente constantemente impulsionada pelo "boom" dos veículos elétricos, estima-se um aumento anual das commodities de níquel até 2020 [3]. A difusão de veículos elétricos e híbridos tem aquecido a indústria de componentes de baterias automotivas, as quais podem apresentar em sua composição cátodos de LCO (óxido de lítio-cobalto), NCA (lítio-níquel-cobalto-alumínio, ou LiNiCoAl) e NMC (lítio-níquel-manganês-cobalto, ou LiNiMnCo), entre outros [4]. Especialistas afirmam que o aumento da demanda por cobalto, a qual deve aumentar em quase oito vezes até 2026, aliada a escassez deste mineral, pode ocasionar uma crise no mercado de carros elétricos [5,6]. Desta maneira, - mercado de níquel e cobalto deve crescer nos próximos anos, juntamente com a busca por tecnologias viáveis de extração e de recuperação destes valores metálicos a partir de depósitos anteriormente considerados marginais.

Recentemente, vários projetos visando a extração de cobre, cobalto e níquel de minérios de sulfeto de baixo teor vêm sendo descritas. No entanto, poucos projetos têm sido apresentados abordando a recuperação desses metais valiosos a partir de minérios lateríticos. Além das rotas convencionais de pirometalurgia e lixiviação sob alta pressão (HPAL) utilizadas mais frequentemente na cadeia produtiva de metais extraídos a partir de minérios de maior teor, tecnologias alternativas baseadas na biolixiviação vêm sendo desenvolvidas buscando tornar viável a exploração de jazidas de baixo teor, conforme ilustrado na Figura $I$.

A biolixiviação é considerada uma alternativa sustentável e econômica para o processamento de minerais com baixo teor. Os processos biohidrometalúrgicos são baseados na atividade metabólica de micro-organismos que, em grande maioria dos processos, catalisama oxidação do ferro e de compostos de enxofre inorgânico reduzidos, produzindo ácido sulfúrico e ferro férrico. Estes agentes lixiviantes contribuem para a dissolução de minerais sulfurados por oxidação, liberandometais para solução, resultando em uma tecnologia verde empregada mundialmente [7-9].

Atualmente, uma parte da produção mundial de cobre já se origina de processos de biolixiviação em pilhas. A biolixiviação em tanques agitados também tem sido comercializada para a recuperação de cobalto, assim como de concentrados de ouro refratários [10-12].

A biohidrometalurgia vem sendo empregada para a extração de cobalto associado à lateritas de níquel. Biswas et al. [13] avaliaram a extração de níquel e cobalto de cromita (níquel, 0,87\%; cobalto, 0,03\%; ferro, 48,88\%; cromo I,88\% e manganês, 0,37\%) das minas de Sukinda de Orissa (Índia) com o filtrado de cultivo do fungo Aspergillus niger, o qual continha ácido oxálico. Embora este ácido desempenhasse o papel principal na lixiviação de metais, outros metabolitos não identificados presentes no filtrado de cultura influenciaram significativamente a dissolução dos metais. As porcentagens de extração foram de aproximadamente $65 \%$ tanto para níquel quanto para cobalto após 21 dias de processo.

Recentemente, o processo Ferredox foi proposto para o tratamento de minérios de laterita limonítica por meio de dissolução anaeróbica redutiva (AnRD), a qual parece ser mais eficaz que a biolixiviação aeróbia por fungos e outras bactérias. Neste processo, a redução

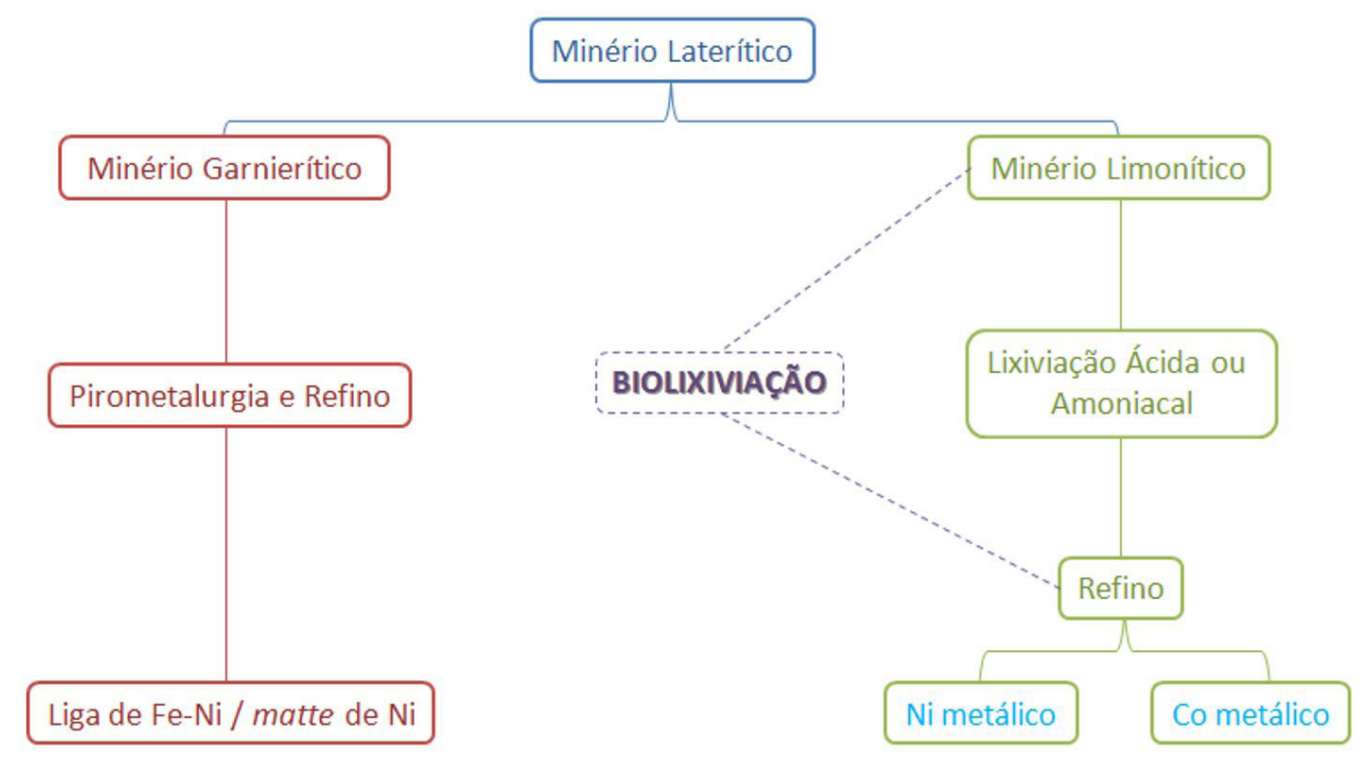

Figura I. Esquema simplificado de rotas de processo de minério laterítico de níquel e cobalto. 
de ferro férrico mediada pela bactéria Acidithiobacillus ferrooxidans pode ser aplicada a uma dissolução aeróbia redutiva de níquel-laterita (AeRD, com um consórcio das bactérias Acidithiobacillus thiooxidans e Acidithiobacillus ferrooxidans). Marrero et al. [14] obtiveram extrações de níquel (53-57\%) e cobalto (55-60\%) em apenas 7 dias de processo combinado AnRD e AeRD. A recuperação de níquel e cobalto em solução de lixiviação de base ferrosa facilita a recuperação dos metais.

Neste contexto, o objetivo deste estudo foi mapear o conhecimento tecnológico do uso da biolixiviação para extração e recuperação de níquel e cobalto a partir de minérios lateríticoscom o intuito de caracterizar o perfil das inovações tecnológicas depositadas nos últimos anos.

\section{METODOLOGIA}

O mapeamento dos pedidos de patentes e tecnologias consistiu na busca pelas palavras-chave "bioleaching", "laterite", "nickel" e "cobalt" simultaneamente nas bases de dados do Google [15] e Patentscope (WIPO) [16] que tem atualização periódica, cuja base importa atualmente patentes de 148 países, incluindo ainda o Tratado de Cooperação de Patentes (PCT), com atualização periódica. Uma busca com a palavra-chave "biolixiviação" também foi realizada na base de dados de patentes depositadas no Instituto Nacional de Propriedade Intelectual (INPI).

As patentes foram tratadas seguindo-se de inserção de seus dados em gráficos plotados em Excel 2010. As pesquisas na base de dados foram atualizadas pela última vez na data de $18 / 05 / 2018$.

\section{RESULTADOS E DISCUSSÃO}

\section{I Distribuição Cronológica das Patentes e a Economia Mineral}

A realização de estudos de prospecção de inovações tecnológicas auxiliana fundamentação dos processos de tomada de decisão a longotermo, colaborando para a elaboração de estratégias de mercado e planos de ação que dispõem circunstâncias futuras prováveis e desejadas em um estreito alinhamentocom a demanda industrial e a economia [17].

$\mathrm{Na}$ prospecção proposta no presente estudo, observou-se a existência de 46 pedidos de patente entre os anos de 1995 e 2017 especificamente no que se diz respeito ao desenvolvimento de biotecnologias a serem empregadas na cadeia produtiva de níquel e cobalto. A análise preliminar da evolução anual dos depósitos das patentes sobre esta temática, ilustrada na Figura 2, sugere um aumento significativo no depósito de patentes nos anos de 2007 e 2008.

Este crescimento do número de depósitos de patentes no final dos anos 2000 pode ser explicado pelo crescimento acelerado da economia chinesa ( $10,7 \%$ a.a.), - qual ocasionou uma alta na demanda global por bens minerais que impulsionou os preços internacionais de commodities $[9,18]$. E, apesar do baixo investimento no setor mineral, o qual somente no Brasil caiu de US\$ 75 bilhões entre 2012 e 2016 , para US\$53,6 bilhões no período de 2014 à 2018 [19], o setor de biohidrometalurgia de níquel e cobalto ainda está ativo quando se analisa a proteção de tecnologias desenvolvidas no setor.

A crise econômica global ocorrida no pós-2008 diminuiu o preço dos metais não-ferrosos como o níquel e o cobalto, porém as inovações biotecnológicas no setor continuaram a serem protegidas. Até 2012 , o níquel foi o metal

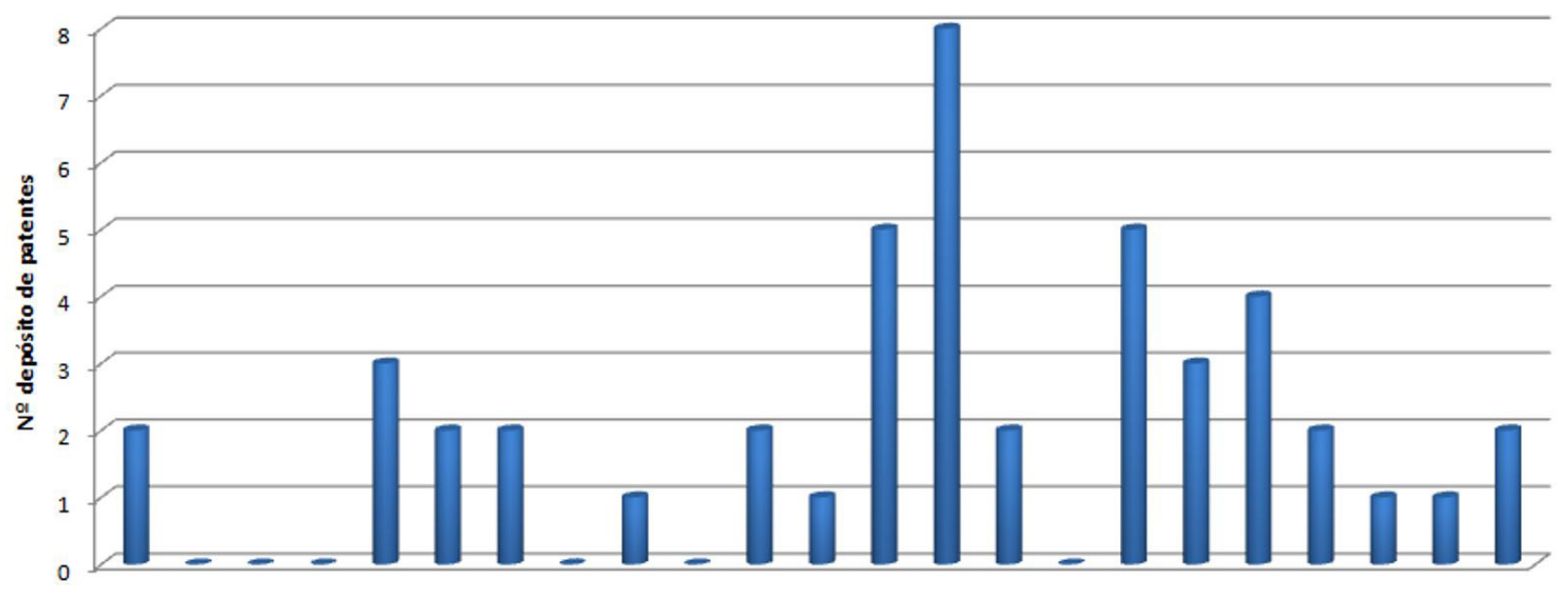

19951996199719981999200020012002200320042005200620072008200920102011201220132014201520162017

Ano de depósito

Figura 2. Distribuição cronológica dos depósitos de patentes sobre a temática biolixiviação de níquel e cobalto de lateritas no período de 1995 a 2017. 
que apresentou um dos maiores crescimentos econômicos, como consequência do crescimento do consumo de aços inoxidáveis, acompanhando de perto o crescimento da produção industrial. Enquanto que o níquel apresentou um crescimento econômico de $4 \%$ no período, outros metais como o zinco $(2,9 \%)$, cobre $(2,8 \%)$ e chumbo $(1,7 \%)$ apresentaram taxas de crescimento menores [2].

A partir de 2012, a demanda chinesa por commodities metálicas diminuiu frente à desaceleração econômica e rebalanceamento dos investimentos com consequente queda dos preços internacionais até 2017. Atualmente, o cenário global ameaça os preços da commodities minerais e metálicas, com o avanço dos ataques dos Estados Unidos à Síria e possíveis sanções ao Irã, além das recentes tensões comerciais envolvendo a China [20].

De acordo com a Figura 3, o preço mensal do cobalto vem crescendo nos dois últimos anos, acompanhado por um discreto aumento no preço mensal do níquel. Isso significa que em contraponto à diminuição do preço dos metais não-ferrosos, os denominados minerais estratégicos, portadores de futuro, têm apresentado uma ascenção generosa no mercado das commodities.

O cobalto, por exemplo, vem sendo chamado de "ouro azul" pelo seu potencial de aplicação em carros elétricos. O cobalto é extraído como produto secundário das minas de cobre e níquel, e sua extração depende da viabilidade econômica destas minas, ou seja, uma queda dos preços dos metais poderia reduzir sua extração e, consequentemente o preço do cobalto aumentaria [22].

Alguns autores consideram ainda que 2016 foi o ano do lítio, 2017 foi o ano do cobalto e 20I8-2020 provavelmente serão os anos do níquel, com os estoques de níquel caindo e os preços do níquel finalmente começando a subir. Esta projeção é decorrente da forte demanda chinesa e global de aço inoxidável e demanda crescente de veículos elétricos usando baterias de alto teor de níquel NMC (8:I:I) [3].
No Brasil, o valor da Produção Mineral Brasileira (PMB) alcançou o patamar máximo de sua história em 2011 com negócios de US\$ 53 bilhões. Porém, a partir de 2012 registrou-se queda gradativa da PMB, chegando a US\$ 24 bilhões em 2016. Estima-se que em 2018, o valor da PMB seja igual a US\$ 34 bilhões, o que significa um crescimento de $58 \%$ nos 2 últimos anos [19]. Um dos grandes desafios do setor metalúrgico, tanto no Brasil quanto no mundo, está em prover e utilizar novas tecnologias para exploração de lateritas a fim de fornecer níquel e cobalto de maneira mais eficiente e sustentável mesmo num ambiente econômico adverso.

\subsection{Distribuição Geográfica das Patentes}

Os depósitos de patentes, no período avaliado, foram realizados em 8 países, incluindo-se ainda o Tratado de Cooperação em matéria de Patentes (PCT) eo Escritório Europeu de Patentes (EPO) como apresentado na Figura 4.

Os EUA dispõem da maior quantidade das tecnologias para biolixiviação depositadas em seu território, totalizando II documentos de patentes registrados, seguido pelo PCT ( 10 depósitos), Austrália (8 depósitos) e Canadá (7 depósitos).Vale ressaltar que as maiores reservas mundiais de níquel pertencem à Austrália (19.000 mil t), seguida por Nova Caledônia ( 12.000 mil t), Brasil ( 9.100 mil t) e Rússia (7.900 mil t). Os Estados Unidos possuem apenas 160 mil t de reservas minerais deste metal [23].

Porém, o número de depósitos de patente não parece estar associado com as reservas mundiais de níquel e cobalto, e sim com o aumento do consumo de níquel em ligas não ferrosas e baterias. Esta demanda crescente está associada a uma série de desenvolvimentos tecnológicos recentes voltados para o desenvolvimento de novos materiais e aplicações.

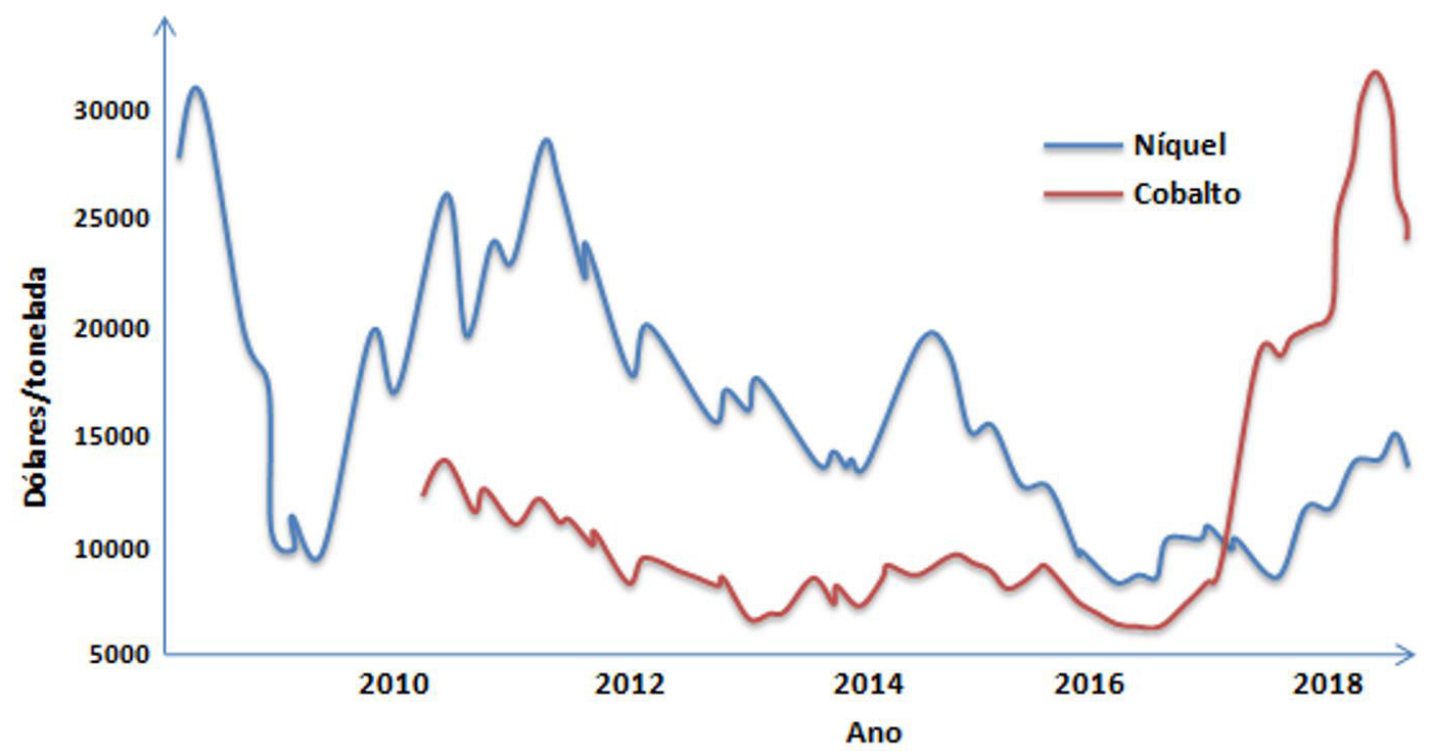

Figura 3. Preço mensal do níquel e cobalto nos dez últimos anos. Fonte: Trading Economics [2I]. 


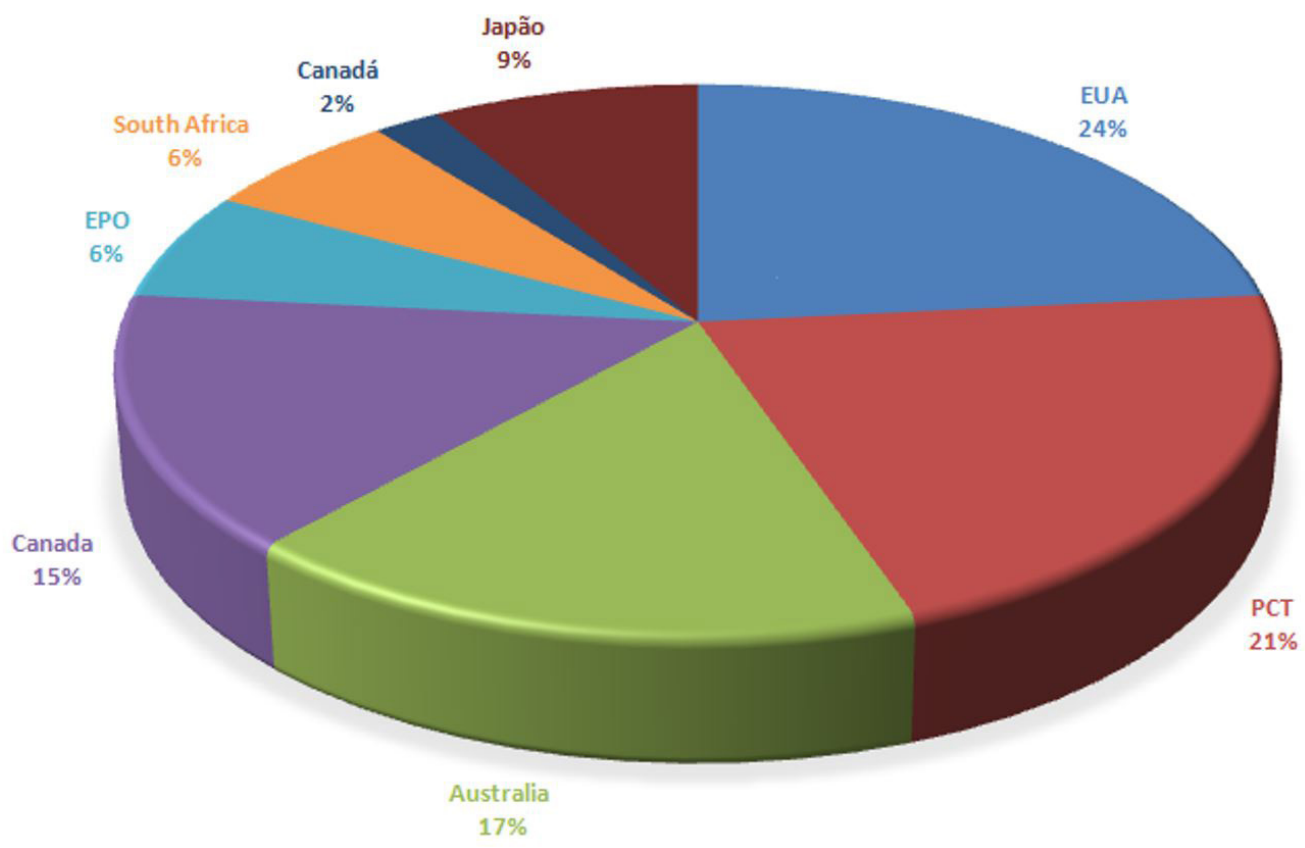

Figura 4. Distribuição geográfica do número de depósitos de patentes prospectados em países de prioridade sobre a temática biolixiviação de níquel e cobalto de lateritas no período de 1995 a 20I7. PCT, Tratado de Cooperação em matéria de Patentes; EPO, Escritório Europeu de Patentes. Fonte: PatentScope [16].

De acordo com pesquisa realizada na base de dados do escritório de patentes dos Estados Unidos (USPTO), esforços tecnológicos recentes têm sido observados na forma de depósitos de privilégios de invenção, para o desenvolvimento, entre outros, de baterias de níquel-zinco para veículos híbridos, de superligas e novos materiais para semicondutores, de turbinas, de discos de memória e de nanomateriais [23].

\section{3 Áreas de Abrangência}

A Classificação Internacional de Patentes (CIP) prevê um sistema hierárquico de símbolos para a classificação de Patentes de Invenção e de Modelo de Utilidade de acordo com as diferentes áreas tecnológicas a que pertencem. A Figura 5 apresenta as áreas de abrangência dos sub-grupos que classificam o processo de extração de compostos metálicos por lixiviação na presença de micro-organismos.

A Figura 5 ilustra as diferentes áreas de abrangência encontradas na distribuição dos documentos de patentes em biolixiviação e tecnologias correlatas, depositadas na OMPI por códigos de classificação internacional (CIP) prospectadas no presente trabalho.

A maioria dos documentos de patentes selecionados está relacionada com a Seção C (Química e Metalurgia) da CIP, enquadrando-se ainda as seções B (Operações de Processamento), $\mathrm{H}$ (Eletricidade) e $\mathrm{F}$ (Aquecimento).

A classe $C 22 B$ (produção ou refino de metais; pré-tratamento de matérias primas) foi a que demonstrou maior frequência entre os depósitos de patentes rastreados, seguida pelas classes C07D (compostos heterocíclicos), BOID (separação), BOIJ (procesos químicos ou físicos),
B22F (trabalho mecânico com pó metálico), $\mathrm{Cl} 25$ (relativo a micro-organismos) e HOIM (baterias).

$\mathrm{Na}$ área de metalurgia de metais não-ferrosos (C22) (Tabela I), os depósitos de patentes são baseados principalmente na extração de compostos metálicos de minérios por via úmida $(\mathrm{C} 22 \mathrm{~B} 3 / 00)$, especialmente por lixiviação $(C 22 B$ 3/4) na presença de soluções inorgânicas ácidas como o ácido sulfúrico (C22B 3/08) com o uso de micro-organismos (C22B 3/18). A maioria das patentes está concentrada na área de obtenção do cobre (C22B I5/00), seguida pela obtenção do níquel ou do cobalto (C22B 23/00) e de metais nobres (C22B II/00).A extração de cobre é citada em um grande número de documentos de patente uma vez que o cobalto também pode ser obtido como subproduto da extração deste metal [24].

\subsection{Inovações em Biomineração de Níquel e Cobalto}

A busca em bases de propriedade intelectual foi realizada no GooglePatents e sites livres de busca de patentes como o INPI-BR e WIPO. Os resultados de busca de anterioridades para a área de mineração no tema de biolixiviação de níquel e cobalto estão descritos sucintamente a seguir:

Os documentos de patentes selecionados nas pesquisas nos bancos de dados do Google Patents e WIPO estavam relacionados e foram analisados conjuntamente(Tabela 2). Cerca de $69 \%$ dos documentos de patentes depositados pertencem à empresa americana BHP MineralsInternational INC.

Dentre os 10 documentos prospectados na base de dados do INPI-BR, apenas um documento se refere à biolixiviação de um minério laterítico para a recuperação de 


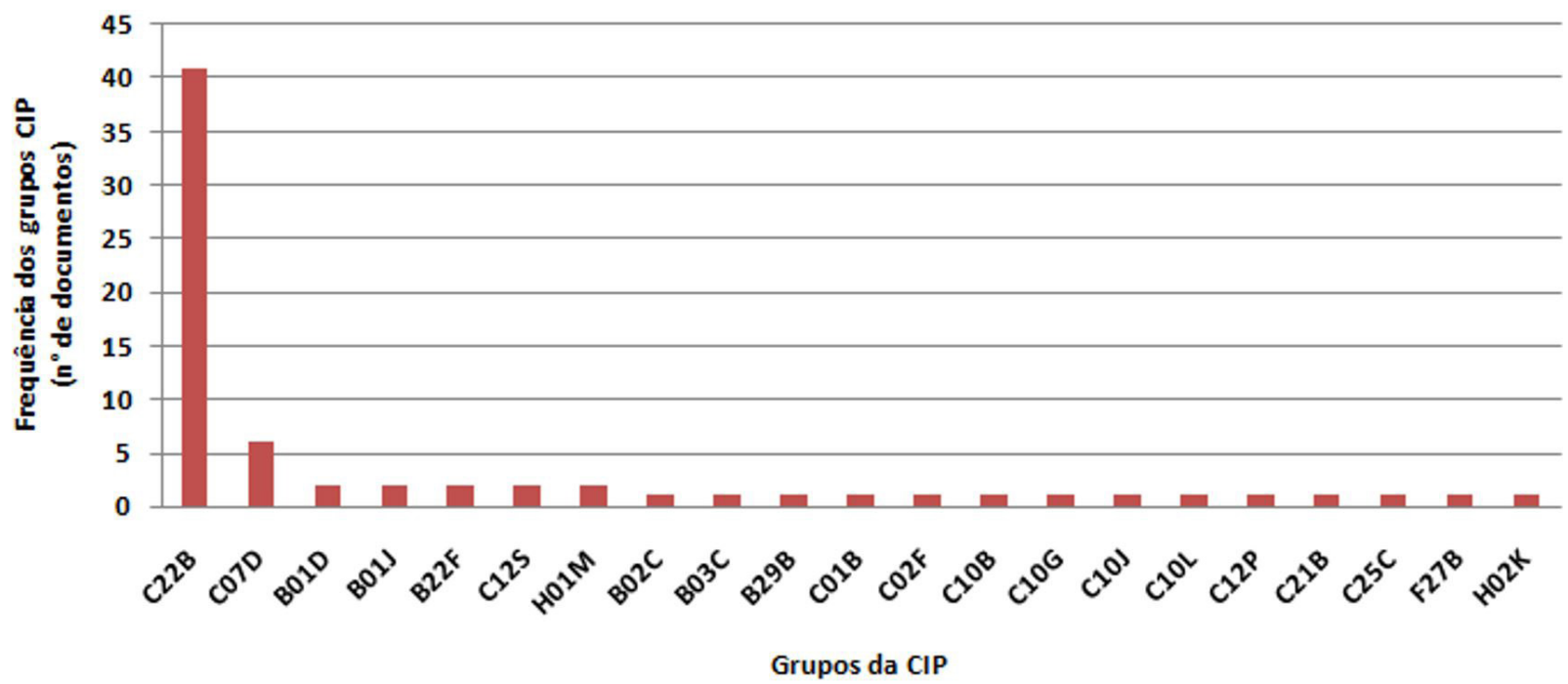

Figura 5. Frequência dos grupos da Classificação Internacional de Patentes utilizados nos depósitos de patentes relacionados à temática biolixiviação de níquel e cobalto de lateritas no período de 1995 a 2017. Fonte: PatentScope [16].

Tabela I. Áreas de abrangência dos sub-grupos da classificação internacional de patentes C22B relacionadas ao processo de biolixiviação

\begin{tabular}{|c|c|c|c|c|c|}
\hline \multicolumn{6}{|c|}{ Código CIP } \\
\hline \multirow[t]{6}{*}{ Seção C } & Química: M & & & & \\
\hline & Classe C22 & \multicolumn{4}{|c|}{ Metalurgia: ligas ferrosas ou não-ferrosas } \\
\hline & & \multirow[t]{4}{*}{ Subclasse C22B } & $\begin{array}{l}\text { Produção ou refino } \\
\text { metais }\end{array}$ & & \\
\hline & & & Grupo C22B 3/00 & \multicolumn{2}{|c|}{$\begin{array}{l}\text { Extração de compostos metálicos de minérios } \\
\text { ou concentrados por processos a úmido }\end{array}$} \\
\hline & & & Subgrupos & C22B $3 / 4$ & por lixiviação \\
\hline & & & & C22B 3/18 & $\begin{array}{l}\text { com auxílio de } \\
\text { micro-organismos ou } \\
\text { enzimas }\end{array}$ \\
\hline
\end{tabular}

Tabela 2. Número de documentos de patente rastreados

\begin{tabular}{clc}
\hline Banco de Dados & \multicolumn{1}{c}{ Palavras-chave } & No de Documentos $^{\circ}$ \\
\hline Google & Bioleaching; laterite; nickel; cobalt & 46 \\
WIPO & Bioleaching; laterite; nickel; cobalt & 42 \\
INPI-BR & Biolixiviação & 10 \\
\hline
\end{tabular}

níquel. A patente PI 96I2802-0 BI "Método para recuperação de níquel a partir de minérios lateríticos, por meio de biolixiviação" trata de um método de biolixiviação para recuperação de níquel de minérioslateríticos e sulfídicos contendo níquel ou concentrados dos mesmos. O minério, ou na forma de uma pasta, um monte, ou uma carga em uma cuba é biolixiviado durante tempo suficiente para realizar a dissolução do níquel no minério, o qual é separado da solução. O níquel é, então, seletivamente extraído da solução usando-se uma resina de troca de íons, e o níquel, após disso, extraído da resina usando-se um ácido mineral. Trata-se de um pedido de proteção da empresa americana BHP MineralsInternational, Inc., que prescreveu no ano de 2012.
As principais reivindicações tecnológicas das patentes prospectadas nas bases Google Patents e WIPO estão resumidas na Figura 6.

A biolixiviação é o método de extração proposto em quase a totalidade de documentos rastreados. A biolixiviação direta ocorre quando o minério é colocado diretamente em contato com os micro-organismos que atuarão na biossolubilização dos metais de interesse [24-26]. A biolixiviação indireta pode ser considerada um método de lixiviação do minério com o uso de metabólitos microbianos produzidos sem o contato direto dos micro-organismos com a amostra mineral [27-29]. Neste último caso também podem ser utilizados processos combinados utilizando soluções de 


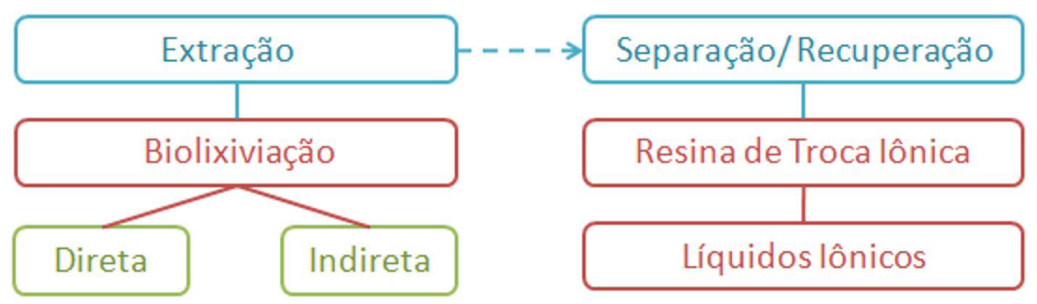

Figura 6. Processos hidrometalúrgicos utilizados na extração, separação e recuperação de níquel e cobalto de acordo com os depósitos de patentes relacionados à temática biolixiviação de níquel e cobalto de lateritas no período de 1995 a 2017.

lixiviação mistas as quais podem conter proporções de ácidos clorídrico, sulfúrico e/ou nítrico; além dos ácidos formados pela atividade bacteriana (cítrico, oxálico, málico, acético, entre outros) [30].

Dentre os documentos rastreados no presente artigo, o uso de biolixiviação direta com micro-organismos autotróficos (produtores de ácido sulfúrico) e heterotróficos (produtores de ácidos orgânicos) é a metodologia mais citada.

$O$ documento mais antigo rastreado nesta busca de patentes aborda o uso da biolixiviação para a recuperação de níquel metálico a partir de minérios lateríticos e sulfídicos. No caso dos minérios lateríticos, a solução de lixívia conterá ao menos um micro-organismo pertencente ao gênero Acidithiobacillus e um nutriente para o crescimento microbiano (enxofre ou pirita, para favorecer a produção biológica de ácido sulfúrico), em uma faixa de $\mathrm{pH}$ entre I e 3 . $\mathrm{O}$ níquel extraído seria recuperado seletivamente com o uso de resinas de troca iônica [3I].

Duyvesteyn e Li [32] propuseram o uso de um blend de micro-organismos produtores de ácidos orgânicos em um processo integrado de fermentação e biolixiviação de um minério contendo níquel e magnésio. Os inventores sugeriram o uso de um processo para lixiviar uma amostra de níquel laterita com o uso do Aspergillus niger, um fungo capaz de produzir ácido cítrico. A partir de um processo conjunto de fermentação de melaço de cana para a produção de ácido cítrico, o qual também atua como um agente lixiviante da amostra mineral, seria possível tanto a recuperação do níquel metálico quanto a comercialização do ácido cítrico produzido. $\mathrm{O}$ magnésio poderia ser ainda recuperado do processo através da forma de hidróxido de magnésio.

O uso de micro-organismos produtores de ácido cítrico na biolixiviação de níquel e cobalto é citado em outros documentos de patente, como é o caso do fungo Penicillium PSMI I-5 [33]. Outros processos citam o uso de outros ácidos produzidos biologicamente, como o uso de um ácido alifático $\mathrm{Cl}$-C20-carboxílico ou o uso de um micro-organismo que produz um ácido alifático $\mathrm{Cl}-\mathrm{C} 20$-carboxílico. Neste pedido de privilégio de invenção em particular, os autores sugerem o uso de uma segunda etapa de processo para a recuperação de metais constituída da lixiviação da mistura sólida residual na presença de um micro-organismo produtor de ácido sulfúrico [34].

A biolixiviação é uma tecnologia limpa que também vem sendo comumente utilizada em processos integrados envolvendo operações unitárias da hirometalurgia convencional. Neste sentido, o Instituto de Pesquisas de Metais Não-Ferrosos de Pequim (China), vem desenvolvendo um processo de extração de níquel de minérios lateríticos através de um processo integrado utilizando líquidos iônicos e a biolixiviação [35].

O processo descrito na presente invenção utiliza líquidos iônicos à temperatura ambiente, onde o mecanismo de ação consiste no sequestro de íons metálicos pela fase orgânica rica em líquidos iônicos. Com o aumento dopH, a distribuição dos íons metálicos na fase líquida iônica gradualmente aumenta, favorecendo a extração seletiva de íons metálicos na ordem $\mathrm{Co}>\mathrm{Cu}>\mathrm{Ni}$. Se a concentração de níquel laterítico percolado for maior que $500 \mathrm{mg} / \mathrm{L}$, o ácido P204 (dois O-etilhexil) ácido fosfórico) pode ser utilizado como extratante auxiliar.

A grande maioria dos pedidos de privilégios de invenção se refere ao uso de resinas de troca iônica para a recuperação dos valores metálicos, independente do método de extração. Em alguns casos, especialmente os quais utilizam uma amostra mineral com alto teor de ferro, as resinas de troca iônica são utilizadas para a remoção de ferro, sendo o níquel precipitado como hidróxido de níquel. Este composto é então calcinado, fundido e refinado para a produção de um novo produto de níquel metálico com um baixo teor de ferro [36].

\section{CONSIDERAÇÕES FINAIS}

O monitoramento das patentes depositadas é uma ferramenta que deve ser explorada para a elaboração de estratégias de inovação e desenvolvimento de novas tecnologias. As patentes rastreadas sugerem que o estágio de maturação das biotecnologias para aproveitamento de minérios lateríticos de níquel e cobalto através da biolixiviação envolve um grau de complexidade maior que os processos de metalurgia extrativa clássicos usualmente encontrados na mineração e é de aplicação recente, não estando completamente amadurecida. Com a crescente demanda por produtos high-tech que utilizam metais encontrados em jazidas de baixo teor, faz-se necessário delinear as reservas de lateritas que concentram os minerais estratégicos de interesse e estabelecer os investimentos para a implementação de projetos de bioextração a longo termo, uma vez que as tecnologias existentes para minérios lateríticos ainda são pouco usuais e estão em fase de desenvolvimento. 


\section{REFERÊNCIAS}

I Xie Y, Xu Y, Yan L, Yang R. Recovery of nickel, copper and cobalt from low-grade Ni-Cu sulfide tailings. Hydrometallurgy. 2005;80(I):54-58.

2 Rodrigues RL. Definição de capacidade de um depósito médio de níquel laterítico aproveitado através de rota de lixiviação ácida sob pressão [dissertação]. Ouro Preto: Universidade Federal de Ouro Preto; 2007.

3 Bohlsen M. Top 5 nickel miners to consider before the nickel boom [página da internet]. 20 I 8 [atualizada em 28 mar. 20 I8; acesso em 10 out. 20 I8]. Disponível em: https://seekingalpha.com/article/4 I59556-top-5-nickel-minersconsider-nickel-boom

4 Castro BHR, Barros DC, Veiga SG. Baterias automotivas: panorama da indústria no Brasil, as novas tecnologias e como os veículos elétricos podem transformar o mercado global. BNDES Setorial. 20I3;37:443-496.

5 Meyer M. Como o cobalto poder frear (ou não) o avanço dos carros elétricos [página da internet]. 2018 [atualizada em 6 jun. 2018; acesso em 10 out. 2018]. Disponível em: https://www.oficinadanet.com.br/energiaverde/22865como-o-cobalto-poder-frear-ou-nao-o-avanco-dos-carros-eletricos

6 Stringer D, Ritchie M. Ameaça de choque do cobalto é maior risco para carros elétricos [página da internet]. 2018 [atualizada em 22 maio 2018; acesso em 10 out. 2018]. Disponível em: https://economia.uol.com.br/noticias/ bloomberg/2018/05/22/ameaca-de-choque-do-cobalto-e-maior-risco-para-carros-eletricos

7 Vera M, Schippers A, Sand W. Progress in bioleaching: fundamentals and mechanisms of bacterial metal sulfide oxidation—part A. Applied Microbiology and Biotechnology. 2013;97(17):7529-754I.

8 Ahmadi A, Zhezri M, Abdollahzadehb A, Askaric M. Bioleaching of copper, nickel and cobalt from the low grade sulfidic tailing of Golgohar Iron Mine, Iran. Hydrometallurgy. 20I5; I54:I-8.

9 Giese EC. Biolixiviação: uma avaliação das inovações tecnológicas na biomineração de minerais sulfetados no período de 199I a 2015. Tecnologica em Metalurgia, Materiais e Mineração. 2017;3:192-203.

10 Olson GJ, Brierley JA, Brierley CL. Bioleaching review part B: progress in bioleaching: applications of microbial processes by the minerals industries. Applied Microbiology and Biotechnology. 2003;63:249-257.

II Morin DHR, d'Hugues P. Bioleaching of a cobalt-containing pyrite in stirred reactors: a case study from laboratory scale to industrial application. Berlin: Springer Berlin Heidelberg; 2007. p. 35-55.

12 van-Aswegen PC, van Niekerk J, Olivier W. The BIOX ${ }^{\circledR}$ process for the treatment of refractory gold concentrates. In: Rawlings DE, Johnson DB, editor. Berlin: Springer; 2007. p. I-34.

13 Biswas S, Dey R, Mukherjee S, Banerjee PC. Bioleaching of nickel and cobalt from lateritic chromite overburden using the culture filtrate of Aspergillus niger. Applied Biochemistry and Biotechnology. 20 I3; I 70(7): I547- 1559.

14 Marrero J, Coto O, Goldmann S, Graupner T, Schippers A. Recovery of nickel and cobalt from laterite tailings by reductive dissolution under aerobic conditions using Acidithiobacillus species. Environmental Science \& Technology. 2015;49(II):6674-6682.

15 Google Patents. [base de dados na Internet]. [acesso em 18 maio 2018]. Disponível em: https://patents.google.com/

16 World Intellectual Property Organization - WIPO. Patentscope [base de dados na Internet]. [acesso em 18 maio 2018]. Disponível em: https://patentscope.wipo.int/search/pt/search.jsf

17 Mayerhoff ZDVL. Uma análise sobre os estudos de prospecção tecnológica. 2008; I(I):7-9.

18 Passos AM, Gottlieb J. China: os impactos no Brasil de um novo modelo de crescimento [página da internet]. São Paulo: 2014 [atualizada em 31 out. 2014; acesso em 9 out. 2018]. Disponível em: https://www.itau.com. br/itaubba-pt/analises-economicas/publicacoes/macro-visao/china-os-impactos-no-brasil-de-um-novo-modelodecrescimento

19 Instituto Brasileiro de Museus. Economia mineral do Brasil. [página da internet]. São Paulo: IBRAM; 2018 [atualizada em mar. 2018; acesso em 10 out. 2018]. Disponível em: https://portaldamineracao.com.br/wp-content/ uploads/2018/02/economia-mineral-brasil-mar2018-I.pdf?x73853

20 Bomfim R. China: os impactos no Brasil de um novo modelo de cres Geopolítica gera incertezas para commodities minerais e metálicas [página da internet]. São Paulo: Diário Comércio Indústria \& Serviços; 2018 [atualizada em 19 abr. 2018; acesso em 09 out. 20 I8]. Disponível em: https://www.dci.com.br/industria/geopolitica-gera-incertezaspara-commodities-minerais-e-metalicas-1.700492

2I Trading Economics. [base de dados na Internet]. [acesso em 18 maio 2018]. Disponível em: https:// tradingeconomics.com 
22 Reid G. The rush for cobalt and what it means for Evs [página da internet]. Energypost.eu; 2018 [atualizada em 25 abr. 2018; acesso em 10 out. 2018]. Disponível em: https://energypost.eu/the-rush-for-cobalt-and-what-it-meansfor-evs/

23 Carvalho PSL, Mesquita PPD, Ogando LD, Oliveira RP, Araújo EDG. Panorama e tendências do mercado de níquel: estudo realizado em junho de 2015. Rio de Janeiro: BNDES Setorial; 2015. p. 245-296.

24 Hongying Y, Linlin L, Wei L, Xinyi L, Yuanyuan L, Jinghe Z, inventores, Northeastern University, cessionário. Biological selectivity leaching method of low-grade copper-cobalt ore. China patent CN I03572050 A. 2013 Nov 19.

25 Piece W, Stein D, Baden C, Earlastra M, inventores, Mineral Resources International Inc., cessionário. Recovery of metals from ores. Japan patent JP 5 I7206 I B2. 1999 Nov 17.

26 Bashlykova TV, Zhivaeva AB, Zhivayeva A, inventores, Bashlykova TV, Zhivaeva AB, cessionários. Procedure for processing silicate cobalt-nickel ore. Russia patent RU 2395599 C2. 2007 July 09.

27 Yao L, Wen Y, Jiankang D, Hao Q. inventores, Beijing Nonferrous Metals Research Institute, cessionário. Bioleaching process of nickel oxide cobalt ore. China patent CN 100554444 C. 2005 Oct 3 I.

28 Valix M, inventor, The University of Sydney, cessionário. Leaching process. WO 2009I24355 AI. 2008 Apr II.

29 Hill MC, Davies WJ, inventores, Resource Mining Corporation Limited, cessionário. Process for leaching metals from laterite ores. WO 2012119187 Al. 20II Mar 14.

30 Baskov DV, Bychkov AG, inventores, Baskov VD, Gromov EV, Kirillov BA, cessionários. Process for extraction of nickel, cobalt and other metals from laterite ores. WO 2015009204 A2. 2014 July 16.

3I Duyvesteyn WPC, Omofoma MA, inventores, BHP Minerals International Inc., cessionário. Recovery of nickel from bioleach solution. EP $0948655^{\text {a }} 4$. 1995 July 17.

32 Duyvesteyn WPC, Liu H, inventores, BHP Minerals International Inc., cessionário.Process for organic acid bioleaching of nickel ore. EP I26I749 BI. 2000 Mar 7.

33 Pengming L, Wu Y, Chai B, Ying G. inventores, Wuhan Institute of Virology, Chinese Academy of Sciences, cessionário. Penicillium, as well as preparation method and application. China patent CN I0I434909 A. 2008 Dec 19.

34 Stützer M, Krüger K, Bischoff S, Fürstenhof U, inventores, GMBU GES, VGMBU, cessionários. Process for recovering metal from a sulfur-free, metal-containing solid mixture. Germany patent DE I020 I4222979 AI. 20 I4 Nov II.

35 Guocheng Y, Minglin W, Jiankang W, Songtao H, inventores, Beijing Nonferrous Metals Research Institute, cessionário. Process for recovering nickel ion from biochemical lixivium of laterite nickel mine by using room temperature ion liquid. China patent CN I0I457292 A. 2017 Dec 10.

36 Ratchev I, Liu H, Duarte A, Muller, HT, inventores, Bhp Billiton Ssm Development Pty Ltd., cessionário. Production of metallic nickel with low iron content. WO 200802238 I AI. 2006 Aug 23.

Recebido em: 13 Mar. 2019

Aceito em: 15 Set. 2019 